\title{
Optimizing Nutritional Status in Patients Undergoing Radical Cystectomy: A Systematic Scoping Review
}

\author{
Syed M. Alam ${ }^{\mathrm{a}}$, Carrie Michel ${ }^{\mathrm{a}}$, Hilary Robertson ${ }^{\mathrm{a}}$, Juliana T. Camargo ${ }^{\mathrm{a}, \mathrm{b}}$, Brenda Linares ${ }^{\mathrm{c}}$, \\ Jeffrey Holzbeierlein ${ }^{\mathrm{a}, 1}$ and Jill M. Hamilton-Reeves ${ }^{\mathrm{a}, \mathrm{b}, 1, *}$ \\ ${ }^{a}$ Department of Urology, University of Kansas Medical Center, Kansas City, KS, USA \\ ${ }^{\mathrm{b}}$ Department of Dietetics and Nutrition, University of Kansas Medical Center, Kansas City, KS, USA \\ ${ }^{\mathrm{c}}$ Department of Research and Learning, Dykes Library, University of Kansas Medical Center, Kansas City, \\ KS, USA
}

Received 14 October 2020

Accepted 20 June 2021

Pre-press 3 July 2021

Published 13 December 2021

\begin{abstract}
.
BACKGROUND: Nutrition is a modifiable risk factor for patients undergoing multimodal oncologic interventions and plays a major supportive role in the setting of bladder cancer. For patients undergoing radical cystectomy (RC), malnutrition is associated with increased postoperative complications and mortality.

OBJECTIVES: The purpose of this scoping review is to characterize the role of nutritional interventions for patients undergoing $\mathrm{RC}$ for bladder cancer.

METHODS: A multi-database systematic scoping review based on the Preferred Reporting Items for Systematic Reviews extension for Scoping Reviews (PRISMA-ScR) guidelines was performed. Search terms were developed a priori to identify clinical trials that focused on nutritional interventions for patients with bladder cancer undergoing RC. Eligible articles were original research articles or abstracts from clinical trials evaluating nutritional interventions in adult patients undergoing RC. Articles were excluded if they did not focus on a nutritional intervention, if patients did not carry a diagnosis of bladder cancer, or if RC was not performed. Articles were reviewed independently by the authors, and inclusion/exclusion were based on consensus agreement.

RESULTS: A total of 83 articles were identified, of which 17 were included in the final analysis. A total of 49 articles were excluded during abstract screening. An additional 17 articles were excluded based on the review of full-text articles. Results of the scoping review suggest that data on the use of nutritional screening, assessment, and intervention for patients undergoing RC are scarce. Although parenteral nutrition (PN) appears to be associated with greater complications after RC, early introduction of food postoperatively or feeding enterally offers benefit and immunonutrition supplements with a focus on a high protein diet have the potential to better optimize surgical outcomes.

CONCLUSIONS: Although the prevalence and consequences of malnutrition among patients undergoing RC are wellestablished, there are limited data evaluating the use of nutritional screening, assessment, and interventions for this population. The pursuit of future clinical trials in this space is critical.
\end{abstract}

Keywords: Urinary bladder neoplasms, cystectomy, malnutrition, sarcopenia, perioperative period, immunonutrition

\footnotetext{
${ }^{1}$ Co-senior authors.

${ }^{*}$ Correspondence to: Jill M. Hamilton-Reeves, PhD, RD, CSO, Associate Professor, Department of Urology, University of Kansas
}

Medical Center, 3901 Rainbow Blvd. Kansas City, KS 66160, USA. Tel.: +1 9135887650 (711 TY); E-mail: jhamilton-reeves@ kumc.edu. 


\section{INTRODUCTION}

Neoadjuvant chemotherapy (NAC) followed by radical cystectomy (RC) with urinary diversion and pelvic lymphadenectomy is the standard of care for patients with muscle-invasive bladder cancer (MIBC) $[1,2]$. Despite the widespread practice, $\mathrm{RC}$ remains a morbid operation with 90-day complication rates approaching $64 \%$ and 30-day mortality rates of $1.5-2.7 \%$ [3-5]. Although progress has been made in improving outcomes through enhanced recovery after surgery (ERAS) protocols, further optimization of patients undergoing RC remains critical [6]. ERAS pathways preserve gut function after RC and have opened an additional avenue for intervention, namely perioperative nutrition [7]. Nutritional status is an important modifiable risk factor for patients undergoing major surgery [8]. The purpose of this scoping review is to elucidate the role of nutrition interventions in the perioperative period for patients undergoing RC for MIBC.

Malnutrition is a state of nutritional imbalance in which dietary intake is unable to meet the needs of the body. In 2012, the American Academy of Nutrition and Dietetics (AND) and the American Society for Parenteral and Enteral Nutrition (ASPEN) described six defining characteristics of malnutrition, including: unintentional weight loss, inadequate dietary intake, muscle loss, subcutaneous fat loss, fluid accumulation, and diminished functional status as measured by handgrip strength [9]. Patients with two or more criteria under this definition are considered malnourished. Malnutrition among bladder cancer patients ranges between $16-55 \%$ depending on how malnutrition is measured $[8,10]$. The prevalence of malnutrition before $\mathrm{RC}$ has been reported in multiple studies, with $21-55 \%$ of patients being considered at risk for malnutrition and $28 \%$ of patients being identified as moderately-severely malnourished [11-13]. In RC, malnutrition is associated with both increased postoperative complications and mortality [13, 14].

$\mathrm{RC}$ has been shown to lead to major catabolic changes, including unmitigated protein losses, net fatty oxidation, and persistent weight loss [14, 15]. Lambert et al. demonstrated an increased risk of overall and cancer-specific mortality in a cohort of patients with low albumin levels undergoing RC [16]. A study by Gregg et al. demonstrated similar results in which low albumin, BMI $<18.5 \mathrm{~kg} / \mathrm{m}^{2}$, and $>5 \%$ weight loss before surgery were associated with increased 90-day and overall mortality for patients undergoing RC [14]. Sarcopenia, a condition of diminished muscle mass and function closely related to malnutrition, is associated with an increased risk of cancer-specific mortality and lower survival [17]. Sarcopenia is also a risk factor for postoperative complications in RC and is often not addressed, alluding to an unmet need that could adversely impact surgical outcomes $[18,19]$.

Few clinical trials have sought to evaluate the impact of perioperative nutrition interventions for patients undergoing $\mathrm{RC}$, particularly for patients with MIBC who are at increased risk for malnutrition. This current review examines the evidence of the impact of perioperative nutrition interventions for patients with MIBC undergoing RC, based on the following question: What are effective nutrition strategies and interventions for MIBC patients undergoing $R C$ ? The decision to pursue a scoping review was based on an absence of a standard for nutritional intervention for MIBC. Such a review assesses the extent of available literature and allows for critical evaluation of previously reported trials. By completing this scoping review, the authors aim to provide a meaningful resource for clinicians aiming to improve outcomes for patients undergoing cystectomy through nutrition-based interventions. Although outside the scope of the systematic review, nutrition screening and assessment tools and preoperative optimization of functional status are also discussed to help clinicians integrate this care into their practices.

\section{METHODS}

A systematic scoping review of the literature was designed and performed according to the recommendations of the Preferred Reporting Items for Systematic Reviews extension for Scoping Reviews (PRISMA-ScR) to identify nutrition intervention studies in RC [20]. The electronic bibliographic search was carried out in the following databases: Publisher Medline (PubMed), Excerpta Medica Database (EMBASE), and Cumulative Index of Nursing and Allied Health Literature (CINAHL).

The search strategy used descriptors identified in the Medical Subject Headings (MeSH) catalog available through the United States National Library of Medicine. In addition to MeSH terms, the "entry terms" were combined by the Boolean operator OR. The descriptors used were "Nutrition", "Nutrition screening", "Nutrition support", "Nutrition therapy", "Nutrition assessment", "Nutrition intervention", 


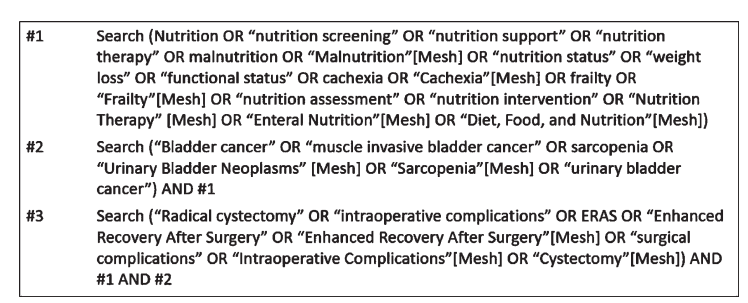

Fig. 1. PubMed complete search.

"Enteral nutrition", "Diet, food, and nutrition", "Malnutrition", "Nutrition status", "Weight loss", "Functional status", "Cachexia", "Frailty", "Bladder cancer", "Muscle invasive bladder cancer", "Sarcopenia", "Urinary bladder neoplasms", "Urinary bladder cancer", "Radical cystectomy", "Intraoperative complications", "Enhanced recovery after surgery", "Surgical complications", and "Cystectomy", which were combined through the Boolean "OR" and "AND" operators. The complete search for PubMed appears in Fig. 1.

The review eligibility criteria included: original studies and conference abstracts from randomized clinical trials or clinical trials, publication in peerreviewed journals, studies evaluating nutritional interventions in patients undergoing $\mathrm{RC}$, inclusion of adults and/or elderly patients (aged over 18 years), and articles written in English. Studies not meeting these criteria were excluded. Based on the paucity of literature in this field, retrospective reviews were included, and there were no restrictions on the year of publication.

After completing the literature search, abstracts were collected and distributed for reevaluation by the authors of this review. Inclusion and exclusion of an abstract were determined by author consensus based on the inclusion criteria mentioned above and the purpose of the review. Full articles were then individually reviewed and evaluated for content directly relevant to the study question. The following data from the full text of each study were entered into a Microsoft Excel spreadsheet by the lead author: population - geographical location, number of participants, percentage of participants treated with NAC; intervention - brief description of the intervention and control procedures, duration of the intervention, and type of feeding (parenteral, enteral or oral); study design and primary study objectives; outcomes measured - postsurgical complications. After all articles were read and evaluated, the second round of exclusion was performed based on the initial criteria and author consensus. Articles not identified in the initial literature search could be included in the final review if they met the inclusion and exclusion criteria and were felt to contribute significantly to the field (Fig. 2). Publications were broadly categorized based on the use of (1) parenteral nutrition (PN), (2) enteral nutrition (EN, tube feeding), or (3) oral nutrition supplements. All articles included in the final review were agreed upon unanimously by the authors, and the process was guided by the librarian (Table 1).

\section{RESULTS}

\section{Overview}

A total of 89 articles were identified after completion of the literature search, and three additional articles from grey literature were added for review. Nine duplicates were removed resulting in 83 articles for preliminary review. After preliminary evaluation of abstracts, a total of 49 studies met criteria for exclusion based on the objectives of the review. Of the remaining 34 articles, a total of 17 met inclusion criteria based on the content of the full publication. Articles were excluded if a nutrition-based intervention was not performed $(n=12)$, or the article was a conference abstract from published literature $(n=5)$. The remainder of the articles were selected to be included in the final review (Fig. 2). For these articles, publication dates ranged from 1984 [21] to 2019 [22]. The sample sizes ranged from 12 [23] to 200 [24] individuals. Of the 17 articles, one was an abstract-only [25], one was an abstract for a trial still in progress [24], and 15 were original articles [10, 21-24, 26-36].

\section{Parenteral nutrition}

A total of six studies aimed to evaluate the impact of PN on patients undergoing RC. PN has been trialed in the postoperative period following cystectomy and has the theoretical advantage of bypassing issues of malabsorption. It may, however, be associated with undesirable complications. In 1984, Bonau et al. reported evidence illustrating the benefits of amino acid-based nutrition support solutions. In this study, a 5\% dextrose solution (D5W) was compared to three different formulations of branched chain amino acid (BCAA) solutions: one containing 25\% BCAA, one with $45 \%$ BCAA and low amounts of leucine, and a third containing $45 \%$ BCAA and higher amounts of leucine. Results indicated that the high leucine solution offered the highest nitrogen balance in the 


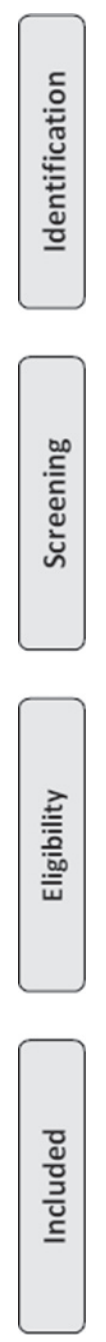

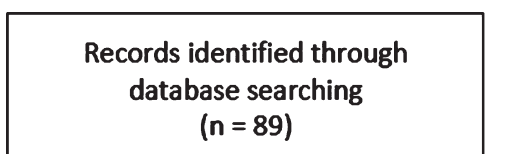

$(n=89)$
Additional records identified through other sources $(n=3)$

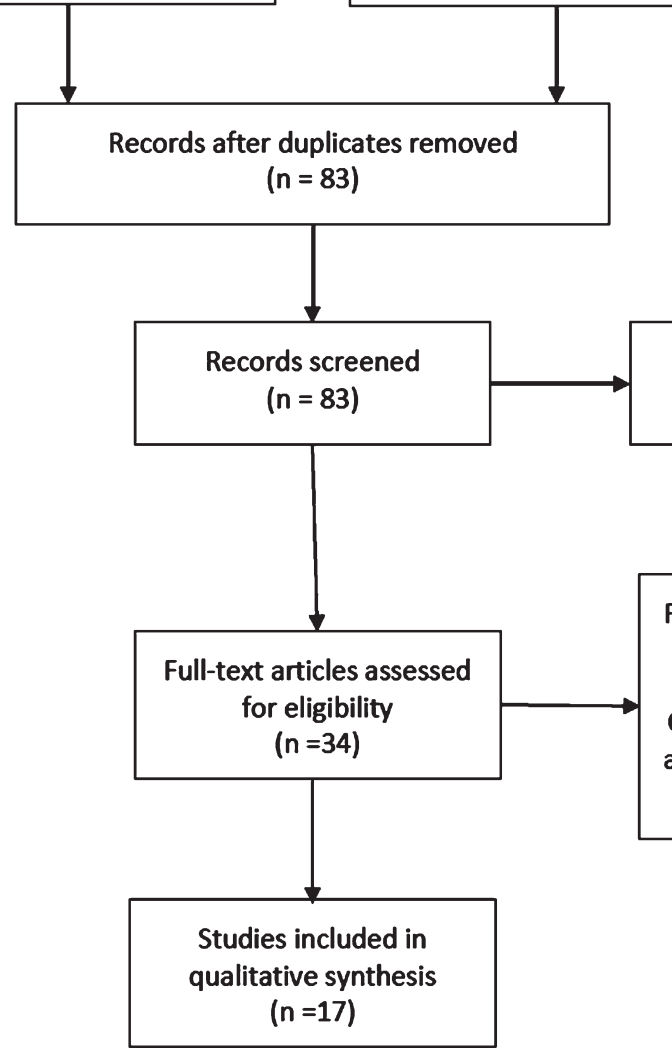

Records excluded

$(n=49)$

Full-text articles excluded,

not a nutrition

intervention $(n=12)$

Conference abstract from

a published original article

$(n=5)$

Fig. 2. PRISMA-ScR Flow Diagram.

postoperative period $(p<0.01)$; however, a comparison to normal intake was not measured concomitantly [21].

In 1986, Hensle et al. published the findings of a randomized controlled trial (RCT) to evaluate the effects of total parenteral nutrition (TPN) on metabolism in the immediate postoperative period after RC. Patients were randomized to receive either D5W or TPN after RC, and measurements of nitrogen balance, gas exchange, and urinary norepinephrine were taken for one week. Total nitrogen depletion was noted in the D5W group as compared to the development of nitrogen equilibrium in the TPN group. Patients receiving TPN also had a greater than expected resting energy expenditure and increased levels of urinary norepinephrine, suggesting an increase in sympathetic activity and elevated metabolic rate [23]. In a retrospective study of this same cohort, the administration of TPN was associated with a significantly reduced length of stay (17 vs. 24 days, $p<0.002)$ compared to the D5W group [27].

Several studies have compared TPN to regular oral intake, and there is evidence that early postoperative oral intake of a regular diet is feasible. In 2013, Roth et al. published the findings of a RCT comparing TPN to regular oral intake in the first five days after RC with a focus on outcomes. Patients receiving TPN were more likely to experience postoperative complications $(69 \%$ vs. $49 \%, p=0.013)$ including infection ( $32 \%$ vs. $11 \%, p=0.001)$ without a difference in time to gastrointestinal recovery and length of stay [28]. The benefits of TPN after RC were further refuted in a trial by Vidal et al. which compared cancer 
Table 1

Description of studies included in the scoping review

\begin{tabular}{|c|c|c|c|c|c|c|c|c|}
\hline Author/year/location & Study design & $\mathrm{N}$ & Primary Objective & Intervention & Control & Duration & NAC & Complications measured \\
\hline \multicolumn{9}{|l|}{ Parenteral Nutrition } \\
\hline $\begin{array}{l}\text { Bonau/1984/USA } \\
\text { [21] }\end{array}$ & $\begin{array}{l}\text { Prospective } \\
\text { clinical trial }\end{array}$ & 25 & $\begin{array}{l}\text { To compare infusion of } \\
\text { dextrose at } 30 \mathrm{kcal} / \mathrm{kg} / \mathrm{day} \\
\text { with three solutions: } \\
\text { dextrose+ }+25 \% \text { BCAA, } 45 \% \\
\text { BCAA low in leucine, } 45 \% \\
\text { BCAA high in leucine and } \\
\text { investigate the effects on } \\
\text { nitrogen balance and } \\
\text { whole-body protein } \\
\text { turnover }\end{array}$ & $\begin{array}{c}\text { Dextrose with } 25 \% \text { BCAA, } \\
\text { dextrose and } 45 \% \text { BCAA } \\
\text { with lower leucine content, } \\
\text { or dextrose and } 45 \% \text { BCAA } \\
\text { with high leucine content }\end{array}$ & Infusion of D5W & Post RC for 7 days & NA & $\begin{array}{l}\text { Paralytic ileus, sepsis, } \\
\text { infections }\end{array}$ \\
\hline $\begin{array}{l}\text { Hensle/1985/USA } \\
\text { [23] }\end{array}$ & $\begin{array}{l}\text { Prospective } \\
\text { clinical trial }\end{array}$ & 12 & $\begin{array}{l}\text { To define the metabolic } \\
\text { changes associated with } \\
\text { cystectomy and to } \\
\text { demonstrate the metabolic } \\
\text { effects of nutritional } \\
\text { support on cystectomy } \\
\text { patients }\end{array}$ & $\begin{array}{l}\text { TPN composed of glucose } \\
\text { and amino acids }\end{array}$ & Infusion of D5W & $\begin{array}{l}\text { Started } 24 \text { to } 48 \text { hours post } \\
\text { RC and lasted for } 1 \text { week }\end{array}$ & NA & $\begin{array}{l}\text { Infection measured by } \\
\text { leucocyte count }\end{array}$ \\
\hline $\begin{array}{l}\text { Askanazi/1986/ } \\
\text { USA [27] }\end{array}$ & $\begin{array}{l}\text { Retrospective } \\
\text { clinical trial }\end{array}$ & 35 & $\begin{array}{l}\text { To investigate the immediate } \\
\text { initiation of TPN after RC } \\
\text { and its impact on hospital } \\
\text { LOS }\end{array}$ & $\begin{array}{l}\text { TPN solution (glucose or } \\
\text { lipid system) }\end{array}$ & Infusion of D5W & Post RC for 6 to 7 days & NA & $\begin{array}{l}\text { Hospital LOS, infection, } \\
\text { wound dehiscence, } \\
\text { mortality }\end{array}$ \\
\hline $\begin{array}{l}\text { Roth/2013/ } \\
\quad \text { Switzerland [28] }\end{array}$ & $\begin{array}{l}\text { Prospective } \\
\text { RCT }\end{array}$ & 157 & $\begin{array}{l}\text { To evaluate the impact of } \\
\text { TPN versus oral nutrition } \\
\text { alone after surgery on } \\
\text { recovery and postoperative } \\
\text { complications }\end{array}$ & $\begin{array}{l}\text { TPN infusion of Nutriflex® } \\
\text { special } 70 / 240 \text { combined } \\
\text { with } 30 \text { IU human insulin } \\
\text { and } 1875 \text { IU heparin and } \\
\text { oral intake ad libitum }\end{array}$ & $\begin{array}{l}\text { Ringer's lactate solution, } \\
\text { potassium substitution and } \\
\text { oral intake ad libitum }\end{array}$ & $\begin{array}{l}\text { Started } 24 \text { hours post } \mathrm{RC} \text { and } \\
\text { lasted for } 5 \text { days }\end{array}$ & $19 \%$ & $\begin{array}{l}\text { Infection, acute respiratory } \\
\text { distress syndrome, } \\
\text { gastrointestinal including } \\
\text { ileus and/or bowel } \\
\text { obstruction, postoperative } \\
\text { hematoma, } \\
\text { thromboembolisms, } \\
\text { delirium/agitation, } \\
\text { lymphocele, peripheral } \\
\text { arterial ischemia, wound } \\
\text { dehiscence }\end{array}$ \\
\hline $\begin{array}{l}\text { Vidal/2016/ } \\
\quad \text { Switzerland [29] }\end{array}$ & $\begin{array}{l}\text { Prospective } \\
\text { RCT }\end{array}$ & 155 & $\begin{array}{l}\text { To assess the impact of TPN } \\
\text { versus oral nutrition alone } \\
\text { on long-term oncological } \\
\text { and functional outcomes } \\
\text { Same cohort as Roth } 2013 \\
\text { [28], secondary paper. }\end{array}$ & $\begin{array}{l}\text { TPN infusion of Nutriflex }{ }^{\circledR} \\
\text { special } 70 / 240 \text { combined } \\
\text { with } 30 \text { IU human insulin } \\
\text { and } 1875 \text { IU heparin and } \\
\text { oral intake ad libitum }\end{array}$ & $\begin{array}{l}\text { Ringer's lactate solution and } \\
\text { potassium substitution and } \\
\text { oral intake ad libitum }\end{array}$ & $\begin{array}{l}\text { Started } 24 \text { hours post } \mathrm{RC} \text { and } \\
\text { lasted for } 5 \text { days }\end{array}$ & $19 \%$ & $\begin{array}{l}\text { Stomach aches, flatulence, } \\
\text { burping/belching, fecal } \\
\text { urgency, diarrhea, } \\
\text { constipation, nausea, stool } \\
\text { incontinence }\end{array}$ \\
\hline $\begin{array}{r}\text { Declercq/2015/ } \\
\text { Belgium [36] }\end{array}$ & $\begin{array}{l}\text { Prospective } \\
\text { non- } \\
\text { randomized } \\
\text { before-after } \\
\text { trial }\end{array}$ & 94 & $\begin{array}{l}\text { To explore the impact of PN } \\
\text { versus oral nutrition on } \\
\text { LOS from surgery to } \\
\text { discharge }\end{array}$ & $\begin{array}{l}\text { Oral nutrition protocol } \\
\text { (consisting of liquids with } \\
\text { advancement of easy to } \\
\text { digest foods) }\end{array}$ & $\begin{array}{l}\text { PN infusion (polyaminoacids, } \\
\text { glucose, lipids and } \\
\text { electrolytes) combined with } \\
\text { multivitamin powder and } \\
\text { trace elements }\end{array}$ & Started immediately after RC & NA & $\begin{array}{l}\text { Infections, fistulas or leaks, } \\
\text { bleeding or hematoma, } \\
\text { gastro-intestinal, } \\
\text { cardiopulmonary, } \\
\text { neurologic, pain }\end{array}$ \\
\hline
\end{tabular}


Table 1

Continued

\begin{tabular}{|c|c|c|c|c|c|c|c|c|}
\hline \multirow{2}{*}{\multicolumn{3}{|c|}{$\begin{array}{l}\text { Author/year/location Study design } \mathrm{N} \\
\text { Enteral Nutrition (i.e. Tube Feeding) }\end{array}$}} & \multirow[t]{2}{*}{ Primary Objective } & \multirow[t]{2}{*}{ Intervention } & \multirow[t]{2}{*}{ Control } & \multirow[t]{2}{*}{ Duration } & \multirow[t]{2}{*}{ NAC } & \multirow[t]{2}{*}{ Complications measured } \\
\hline & & & & & & & & \\
\hline $\begin{array}{r}\text { McArdle/1986/ } \\
\text { Canada [30] }\end{array}$ & $\begin{array}{l}\text { Prospective } \\
\text { RCT }\end{array}$ & 56 & $\begin{array}{l}\text { To determine whether a } \\
\text { peptide-based enteral } \\
\text { formula could provide a } \\
\text { prophylaxis against } \\
\text { intestinal injury induced by } \\
\text { radiation therapy and to see } \\
\text { if early postoperative } \\
\text { enteral feeding is } \\
\text { achievable }\end{array}$ & $\begin{array}{l}\text { Peptide-based enteral formula } \\
\text { initiated via nasoduodenal } \\
\text { tube or by mouth } 3 \text { days } \\
\text { prior to commencement of } \\
\text { radiation therapy. Post RC, } \\
\text { the enteral formula was } \\
\text { administered via needle } \\
\text { jejunostomy due to } \\
\text { dislodgement issues. }\end{array}$ & $\begin{array}{l}\text { Conventional nutrition } \\
\text { management consisting of } \\
\text { either regular hospital diet } \\
\text { or TPN during radiation; } \\
\text { discontinued after early } \\
\text { results of intervention arm } \\
\text { and all patients placed on } \\
\text { enteral feeding protocol }\end{array}$ & $\begin{array}{l}3 \text { days prior to initiation of } \\
\text { radiation therapy and up to } \\
7 \text { days post RC }\end{array}$ & NA & $\begin{array}{l}\text { Diarrhea, bloody stool, } \\
\text { nausea/vomiting, cramps }\end{array}$ \\
\hline $\begin{array}{l}\text { Daly/1987/USA } \\
\quad[33]\end{array}$ & $\begin{array}{l}\text { Prospective } \\
\text { RCT }\end{array}$ & 28 & $\begin{array}{l}\text { To evaluate clinical and } \\
\text { metabolic effects (weight } \\
\text { gain, improved serum } \\
\text { protein synthesis and } \\
\text { nitrogen balance) with } \\
\text { immediate postoperative } \\
\text { jejunostomy feeding of } \\
\text { either a } 44 \% \text { BCAA or } 15 \% \\
\text { BCAA formula compared } \\
\text { to intravenous solution of } \\
\text { D5W in patients } \\
\text { undergoing RC }\end{array}$ & $\begin{array}{l}\text { Jejunostomy feeding with } \\
\text { either 15\% BCAA or } 44 \% \\
\text { BCAA }\end{array}$ & $\begin{array}{l}\text { Standard therapy and infusion } \\
\text { of D5W }\end{array}$ & Post RC for 7 days & NA & $\begin{array}{l}\text { Gastrointestinal } \\
\text { complications including } \\
\text { nausea, vomiting, bloating, } \\
\text { abdominal pain, abdominal } \\
\text { cramping, diarrhea }\end{array}$ \\
\hline $\begin{array}{l}\text { Maffezzini/2006/ } \\
\text { Italy [32] }\end{array}$ & $\begin{array}{l}\text { Prospective } \\
\text { single-arm } \\
\text { clinical trial }\end{array}$ & 28 & $\begin{array}{l}\text { To investigate the impact of } \\
\text { early postoperative } \\
\text { nutrition using both PN and } \\
\text { EN on the recovery of } \\
\text { normal bowel function, } \\
\text { protein depletion after RC } \\
\text { and observed complications }\end{array}$ & $\begin{array}{l}\text { TPN infusion after RC with } \\
\text { gradual reduction in TPN } \\
\text { and concomitant increase in } \\
\text { EN (Impact@) by way of } \\
\text { jejunostomy }\end{array}$ & No control & $\begin{array}{l}\text { TPN initiated on day of RC } \\
\text { with EN starting POD1 and } \\
\text { continuing until positive } \\
\text { flatus and return of } \\
\text { peristalsis and normal diet } \\
\text { initiated }\end{array}$ & NA & $\begin{array}{l}\text { Complications including } \\
\text { interference in delivery of } \\
\text { EN as well as major } \\
\text { complications such as } \\
\text { re-laparatomy }\end{array}$ \\
\hline $\begin{array}{l}\text { Deibert/2016/USA } \\
\text { [31] }\end{array}$ & $\begin{array}{l}\text { Prospective } \\
\text { RCT }\end{array}$ & 102 & $\begin{array}{l}\text { To investigate the role of } \\
\text { early feeding on } \\
\text { complication rates after RC } \\
\text { and urinary diversion }\end{array}$ & $\begin{array}{l}\text { ERAS fast track pathway; } \\
\text { oral clear liquid diet POD1 } \\
\text { with advancement to } \\
\text { regular diet POD2 and } \\
\text { beyond }\end{array}$ & $\begin{array}{l}\text { Standard of care; NPO until } \\
\text { flatus or bowel movement. } \\
\text { Liquid diet after bowel } \\
\text { movement }\end{array}$ & Post RC & $18 \%$ & $\begin{array}{l}\text { Hospital LOS, complications } \\
\text { post discharge up to } 90 \\
\text { days including ileus, } \\
\text { readmissions, and mortality }\end{array}$ \\
\hline
\end{tabular}


Oral Nutrition Supplements

Prospective

52 To explore the effects of an enriched ONS on

nutritional status and body

composition as well as

improvement in

postoperative outcomes

following RC

Bertrand/2014/

France [34]

Prospective

matched

case-

control

clinical trial

Lyon/2017/USA

[26]

RCT

Hamilton-Reeves/ Prospective

2016/USA [10]

RCT

Hamilton-Reeves/ Prospective

2018/USA [35]

60 Evaluate the effect of

immunonutrition

supplementation on

postoperative complication

144 To investigate the safety,

tolerance, and adherence of preoperative high-arginine ONS

29 To investigate the impact of

an arginine-enriched

immunonutrition ONS on modulating the immune response after $\mathrm{RC}$

perioperative
Kukreja/2019/USA Prospective [25] Abstract

RCT

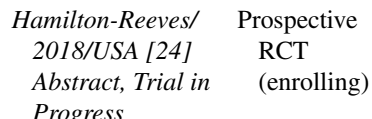

ONS, taken BID, with betahydroxy-methylbutyrate,

prebiotic fiber, and omega 3

fatty acids (Ensure Clinical

Strength ${ }^{\circledR}$ )

ONS with arginine,

nucleotides, and fish oil

omega- 3 fatty acids (Oral

Impact $($ )

ONS with arginine,

omega-3 fatty acids (Impact

Advanced Recovery ( $\left.{ }^{\circledR}\right)$

with arginine,

nucleotides, Vitamin A, an

fish oil omega-3 fatty acids

(Impact Advanced

Recovery $\left.{ }^{\circledR}\right)$

29 To assess the impact of a ONS with arginine,

immunonutrition ONS

versus standard ONS on the

Th1-Th2 balance, the IL- 6

concentration and

nutritional status of RC

patients Same cohort as

Hamilton-Reeves 2016

[10], secondary paper

46 To test tolerability and

acceptability of a

perioperative

immunonutrition regimen

200 To assess and compare the

impact of a perioperative

immunonutrition ONS to a

standard ONS on

postoperative complications

nucleotides, Vitamin A, an

fish oil omega-3 fatty acids

(Impact Advanced

Recovery $\left.{ }^{\circledR}\right)$

\section{High dose arginine}

supplement and omega-3

fatty acid capsules

ONS with arginine,

nucleotides, Vitamin A, an

fish oil omega-3 fatty acids

(Impact Advanced

Recovery $\left.{ }^{\circledR}\right)$ nucleotides, and fish oil

Multivitamin (Member'

Mark (B) BID

weeks post $\mathrm{RC}$

53\% Post discharge complications, readmission rates, and mortality

Matched controls from

hospital database, standar

diet

TID for 7 days prior to RC 13\% Paralytic ileus, infection,

pyelonephritis, pneumonia pelvic abscess, pulmonary embolism, anastomotic fistulae, wound dehiscence, death

Standard of care without oral $237 \mathrm{~m} \mathrm{4x}$ /day for 5 days prior $10 \%$ Hospital LOS, infections, supplements

to $\mathrm{RC}$

overall complications, and readmission rates

ONS (Boost Plus ®)

TID for 5 days prior RC and $38 \%$ Ileus, infection, diarrhea TID for 5 days after RC

ONS (Boost Plus ®)

TID for 5 days prior RC and TID for 5 days post RC

$38 \%$ Weight loss, skeletal muscle loss, and inflammation measured by Th1-Th2 balance and IL-6 levels

\section{NA}

ONS control

s

\footnotetext{
BCAA: Branched-Chain Amino Acids. BID: Twice daily. D5W: Dextrose 5\%. ERAS: Enhanced recovery after surgery. LOS: Length of stay. MCT: Medium-chain triglycerides. NA: Not available.
} BCAA: Branched-Chain Amino Acids. BID: Twice daily. D5W: Dextrose 5\%. ERAS: Enhanced recovery after surgery. LOS: Length of stay. MCT: Medium-chain triglycerides. NA: Not available.
NAC: Neoadjuvant chemotherapy. NPO: Nothing by mouth. ONS: Oral Nutrition Supplement. POD: Postoperative day. RC: Radical cystectomy. RCT: Randomized Clinical Trial. TID: Three times daily. TPN: Total parenteral nutrition. 
outcomes, survival, bowel function, sexual function, and quality of life in patients receiving TPN consisting of polyamino acids, glucose, and electrolytes to patients receiving Ringer's lactate solution and oral fluid intake ad libitum on day of surgery with regular diet advancement after return of bowel sounds. In this trial, patients on oral nutrition without TPN had improved bowel function at three and twelve months after surgery, and no differences were found in recurrence, metastasis, survival, sexual function, or quality of life between groups [29]. Moreover, a study by Declercq et al. showed that progressively advancing patients to a regular diet postoperatively decreased the length of stay compared to using TPN [36].

\section{Enteral nutrition}

By supporting healthy gastrointestinal function and improving the immune response, particularly in the setting of surgical stress, perioperative EN is another potential nutrition intervention. Four studies were identified that evaluated the effects of perioperative $\mathrm{EN}$ in patients undergoing $\mathrm{RC}$, two of which incorporated administration of TPN. In 1986, McArdle et al. demonstrated the benefits of an elemental diet comprised of standardized protein, carbohydrate, and fat supplementation prior to RC. Preoperatively during radiation, the formula was administered in liquid form either by nasoduodenal tube or orally depending on patient preference, and postoperatively the EN was administered via needle jejunostomy as the nasoduodenal tube was dislodged in many of the patients. Gastrointestinal side effects including emesis and diarrhea after surgery were twice as likely in the control group $(p<0.05)$ which received TPN or a regular diet. Patients receiving EN had faster return of flatus and bowel function after surgery $(p<0.001)$ compared to the patients receiving the TPN [30]. Given the results of this study focused on radiation injury compared to surgical insult, these results limit the generalizability to current RC practice guidelines.

In 1987, Daly et al. published findings comparing two different branched-chain amino acid enteral formulas administered via jejunostomy to D5W parenteral infusion. In this trial, jejunostomy feeding led to more gastrointestinal complications than D5W alone (55\% vs. $36 \%$ ), and the authors concluded that jejunostomy feedings had limited usefulness in this population [33]. In 2006, Maffezzini et al. published the findings of a similar study incorporating aspects of both TPN and EN to better assess recovery of normal bowel function, protein depletion, and complications.
In this trial, patients undergoing RC received TPN immediately after surgery with progressive transition to EN via a percutaneous jejunostomy tube placed at the time of surgery. A total of twenty-eight patients were enrolled in the study of which 15 (53.6\%) completed the protocol. As compared to those patients who did not complete the protocol, this method of transition to EN did not improve restoration of normal bowel function, total serum protein, serum albumin, or total lymphocyte count postoperatively [32]. The feasibility of administering early postoperative access to food ad libitum was demonstrated in a clinical trial by Deibert et al. in which patients were randomized to receive a clear liquid diet on postoperative day one with advancement to a regular diet on postoperative day two compared to conventional diet advancement based on bowel function after RC [31]. Although the study did not meet the accrual goal, early oral feeding was well-tolerated and did not affect rates of ileus or length of stay [31].

Overall, feeding via the gastrointestinal tract is well-tolerated and has potential to improve outcomes following RC. Newer surgical care pathways preserve full gut functionality after RC and have opened a new potential avenue for intervention: oral perioperative nutrition $[7,36]$.

\section{Oral nutrition supplements}

Five studies, one abstract, and one protocol abstract were identified that were designed to evaluate the effect of oral nutrition supplementation on outcomes after RC. Given the nutritional demands after surgery, it is logical to consider adding more calories and protein with oral nutrition supplements. In a study by Ritch et al., 61 patients undergoing $\mathrm{RC}$ were randomized to receive either a multivitamin twice a day or a high protein, enriched oral nutrition supplement (ONS) twice a day for two weeks before and four weeks after surgery. The overall complication rate (39\% vs. $43 \%$ ) and rate of high-grade complications (18 vs. $39 \%$ ) were lower in the ONS group, although statistical significance was not achieved in either case. Notably, patients receiving the enriched ONS were significantly less likely to develop sarcopenia (57\% vs $66 \%, p<0.05$ ) [22].

Specialized Immunonutrition (SIM) is fortified with nutrients (L-arginine, omega-3 fatty acids, dietary nucleotides, and vitamin A) that have immediate effects on immune and inflammatory responses, muscle protection, and wound healing after surgery. In 2014, Bertrand et al. demonstrated a significant 
reduction in postoperative complications during the first month after surgery (40\% vs. $76.7 \% p=0.008)$, including paralytic ileus (6.6\% vs. $33 \%)$ and infection (23\% vs. $60 \%)$ after seven days of preoperative $\mathrm{SIM}$ in addition to their regular diet in RC patients as compared to a matched control group [34]. Lyon et al. performed a prospective trial including 40 patients who received a high-arginine SIM supplement five days prior to RC. The authors reported high tolerability and safety of the supplement, although no difference in postoperative infections was achieved [26]. A limitation is that both studies compared the intervention to historical controls.

In a pilot study by Hamilton-Reeves et al., 29 patients were randomized to immunonutrition or standard oral nutrition before and after RC $[10,35]$. The authors highlighted key immunologic changes targetable by immunonutrition including the disruption of Th1-Th2 cell balance to a prominently Th2 response after major surgery. This change impairs cell-mediated immunity and response to infection. Physical insult also leads to the rapid expansion of myeloid-derived progenitor suppressor cells (MDSC) following physical injury, further suppressing T-cells and diminishing plasma arginine levels through expression of arginase-1. Patients in the immunonutrition cohort were found to have lower MDSC counts with a $33 \%$ reduction in postoperative complication rates $(p=0.06)$ and $39 \%$ reduction in infection rates $(p=0.03)$ [10]. Furthermore, the neutrophil:lymphocyte ratio (NLR) was significantly lower in the immunonutrition group compared to those receiving standard ONS 3 hours post incision ( $p=0.039)$; yet, the NLR did not differ significantly when comparing groups over the entirety of the study, suggesting a potential acute immune influence from the immunonutrition supplement. In a subsequent analysis, the shift in Th1:Th2 balance in the immunonutrition group significantly differed from the control group $(p=0.027)$. There was also a significant decrease in IL-6 levels in the immunonutrition group on postoperative day two compared to the control group [35].

This scoping review identified two abstracts, one of which was a protocol abstract, of trials in progress or awaiting publication of results. A study by Kukreja et al. used perioperative supplementation of arginine and omega-3 fatty acid capsules for five days before surgery and 14 days after surgery compared to a control in a total of 46 patients [25]. In addition, a phase III multi-center randomized controlled trial is currently underway comparing immunonutrition to an iso-caloric and iso-nitrogenous control to test the impact on postoperative complications with a goal sample size of 200 patients (ClinicalTrials.gov Identifier: NCT03801954). In this trial, subjects are stratified by urinary diversion type (neobladder vs. ileal conduit) and history of NAC, and nutrition supplements are given three times daily for five days prior and five days immediately following RC [24]. Although the available data on the use of immunonutrition for patients undergoing RC may be considered preliminary, results are promising and suggest that immunonutrition may improve postoperative outcomes through immunomodulation.

\section{DISCUSSION}

The results of this systematic scoping review demonstrate that nutrition status is a key modifiable risk factor for patients undergoing RC. The literature presented here supports the use of oral supplementation and early postoperative feeding. These data also highlight an increased risk with nutrition support of TPN or EN that can be mitigated with guidance from a dietitian for appropriate use. The crossroads between malnutrition and resulting immune dysfunction is highlighted as well. Although larger trials are needed, preliminary data support the safety and efficacy of immunonutrition for patients undergoing RC. Strengths of this review include the use of a scoping methodology to review nutritional interventions for patients undergoing RC. The review is limited, however, by the dearth of evidence available and the exclusion of trials exploring nutritional interventions in non-bladder cancer patients that can potentially be extrapolated to patients undergoing RC. Overall, there is a great need for well-designed clinical trials using nutritional interventions in patients undergoing RC.

The current AUA guidelines for MIBC recommend that all $\mathrm{RC}$ patients at high risk for malnutrition undergo nutrition counseling in preparation for surgery in order to optimize nutritional status [37]. Several validated nutrition screening and/or assessment tools exist to aid clinicians in identifying high-risk patients. One such validated tool, the Patient Generated Subjective Global Assessment (PG-SGA), was designed for use in cancer patients and carries high positive and negative predictive values for identifying malnutrition in patients in the outpatient oncology setting [38]. The PG-SGA uses weight change, dietary intake, gastrointestinal symptoms, 
functional status, metabolic stressors, and physical exam findings to assess muscle, fat stores, and fluid balance.

Although additional screening tools such as the Nutrition Risk Screening (NRS-2002) tool and the Malnutrition Universal Screening Tool (MUST) have been validated in the surgical setting, their predictive value in the setting of bladder cancer is poorly established $[39,40]$. There is evidence that these tools may also be limited in the setting of cancer, as nutritional risk is a complex entity affected not only by biochemical and immunological factors but also by taste/smell alterations, nausea, and dysphagia [41]. Based on its more complete evaluation, the authors of this review prefer the PG-SGA for patients undergoing RC.

More recently, the Controlling Nutritional Status (CONUT) score, a test based on serum albumin, lymphocyte count, and total cholesterol concentration, has shown promise as a means of assessing outcomes in patients with MIBC after RC. In a retrospective evaluation of 347 patients undergoing $\mathrm{RC}$, a high preoperative CONUT score was significantly correlated with older age, advanced T-stage, higher grade, node positive disease, longer median length of stay, and 30-day readmission rate. The CONUT score is an independent predictor of unfavorable cancer-specific mortality and progression-free survival [42].

There is a growing body of evidence to support the evaluation of sarcopenia in RC candidates given demonstrated associations between sarcopenia and adverse outcomes. A change in skeletal muscle mass after NAC is an independent predictor of ileus, perioperative infection, and overall complications $(\mathrm{OR}=0.98, p=0.011)$ following $\mathrm{RC}$ [43]. Rawls et al. revealed that erector spinae muscle density is associated with an increased number of complications after RC $\left(r^{2}=0.032, p=0.014\right)$ [44]. In a multicenter study by Mayr et al., patients with sarcopenia had a significantly worse five-year overall survival $(38.3 \%$ vs. $50.5 \%, p=0.002)$ and cancerspecific survival $(49.5 \%$ vs. $62.3 \%, p=0.016)$ [45]. The Strength, Assistance with walking, Rise from a chair, Climb stairs and Falls (SARC-F) screening tool has been shown to have strong consistency and validity in identifying patients at risk for sarcopenia and can be employed easily in the clinic [46]. Although several studies are underway, there are currently no well-established methods of targeting sarcopenia that meaningfully impact outcomes for patients undergoing major oncologic surgery such as RC. However, the studies by Ritch et al. and Hamilton-Reeves et al. suggest that supplementing extra calories and protein alone may help mitigate muscle wasting after surgery, and consuming fish oil as part of a perioperative nutrition intervention may further modulate the inflammatory response to reduce muscle catabolism after RC [22, 24].

To initiate counseling after identification of highrisk patients, a registered dietitian can assess the patient's ability to tolerate oral intake and may recommend specific foods, oral supplementation, or other targeted medical nutrition therapies. Multiple factors increase the risk of malnutrition and inadequate intake in older adults such as polypharmacy, frailty, decline in physical function, oral dysphagia, cognitive decline, and constipation [47]. Our institution partnered with the Bladder Cancer Advocacy Network (BCAN) to create patient education videos focusing on nutrition and bladder cancer in order to provide guidance for patients with MIBC [48]. In general, MIBC patients undergoing RC should consume adequate protein and calories, before and after surgery, to preserve lean muscle mass and support healing and repair after surgery. Furthermore, routine follow-up appointments are ideal times to rescreen and re-assess nutritional imbalances that may impact this population such as B12 deficiency, renal impairment, and electrolyte abnormalities [49].

Several non-nutrition-based interventions may improve outcomes for malnourished patients based on the critical intersection between nutrition and functional status. Although these interventions do not incorporate nutrition per se, they are valuable means of preparing patients with nutritional deficiencies for the catabolic changes associated with major surgery. In 2016, Jensen et al. evaluated the feasibility, adherence, and efficacy of a two-week pre-habilitation exercise-based program focusing on muscle strength and endurance. Of the participants receiving the intervention, $66 \%$ of intervention participants $(95 \% \mathrm{CI})$ adhered greater than $75 \%$ of the program and muscle power improved by $18 \%$ prior to surgery [50]. In a similar trial, Kaye et al. assessed the feasibility, safety and impact of a four-week physiologist-led pre-habilitation program that led to measurable improvements in body composition, functional fitness and self-reported quality-of-life after RC [51]. In 2019, Minnella et al. conducted a randomized controlled trial evaluating a multimodal pre-habilitation program of exercise, nutrition, and anxiety-reducing techniques. At four weeks post-RC, these patients demonstrated superior physical functional status compared to a notable decline in the control group $(p=0.014)$ [52]. No specific data were 
reported regarding the effects of nutritional intervention within the trial.

In general, the authors of this review recommend screening all patients undergoing $\mathrm{RC}$ with a validated and cancer-specific nutrition screening tool such as the PG-SGA. At our institution, involvement of a nutrition specialist is routinely employed for patients undergoing RC, particularly for those also undergoing NAC. Further data are needed to support the use of a formal exercise program, although regular exercise prior to cystectomy is well-tolerated and likely improves patient recovery following major surgery. Early postoperative introduction of a regular diet supplemented with extra calories and protein is recommended. The precise composition of nutrients to include in nutritional supplementation is not known, but the administration of immunonutrition shows promise as a future means of improving outcomes after RC.

\section{CONCLUSION}

Nutritional status is a key modifiable risk factor that should be addressed in all patients with MIBC at diagnosis and throughout the course of treatment. The physiologic changes that occur with cancer and aging in tandem with the effects of systemic chemotherapy and surgical treatment place patients undergoing $\mathrm{RC}$ at high risk for malnutrition and its associated complications. Further trials focusing on nutritional interventions to improve outcomes for patients with MIBC are critically needed. Through well-designed clinical trials, it will be possible to develop much needed standards for nutritional screening and interventions for patients with bladder cancer.

\section{ACKNOWLEDGMENTS}

The authors have no acknowledgements.

\section{FUNDING}

Support for time was provided by the Nutrition Shared Resource through the National Cancer Institute Cancer Center support grant (P30 CA16852). Support for J. Hamilton-Reeves (JHR) was provided by NIH MERIT award (R37CA218118) from NCI. The contents are solely the responsibility of the authors and do not necessarily represent the official views of the National Institutes of Health.

\section{AUTHOR CONTRIBUTIONS}

All authors of this review contributed equally to concept, design, research, writing, and critical revision. All authors had access to the data.

\section{ETHICAL CONSIDERATIONS}

As a literature review, this study is exempt from any requirement for Institutional Board Review approval.

\section{CONFLICTS OF INTEREST}

Syed M. Alam, Carrie Michel, Hilary Robertson, Juliana T. Camargo, Brenda Linares, Jeffrey Holzbeierlein and Jill M. Hamilton-Reeves have no conflict of interest to report.

\section{REFERENCES}

[1] Witjes JA, Bruins HM, Cathomas R, Compérat EM, Cowan NC, Gakis G, Hernández V, Espinós EL, Lorch A, Neuzillet Y. European Association of Urology guidelines on muscleinvasive and metastatic bladder cancer: summary of the 2020 guidelines, European urology (2020).

[2] N.C.C. Network, NCCN Clinical Practice Guidelines in Oncology (NCCN Guidelines®) Thyroid Carcinoma (Version 2.2020, July 15, 2020), Plymouth Meeting (PA): National Comprehensive Cancer Network, 2020.

[3] Ahmadi H, Montie JE, Weizer AZ, Morgan T, Montgomery JS, Lee CT. Patient psoas muscle mass as a predictor of complications and survival after radical cystectomy. Current Urology Reports. 2015;16(11):1-7.

[4] Shabsigh A, Korets R, Vora KC, Brooks CM, Cronin AM, Savage C, Raj G, Bochner BH, Dalbagni G, Herr HW. Defining early morbidity of radical cystectomy for patients with bladder cancer using a standardized reporting methodology. European Urology. 2009;55(1):164-76.

[5] Aziz A, May M, Burger M, Palisaar R, Trinh Q, Fritsche H, Rink M, Chun F, Martini T, Bolenz C. PROMETRICS 2011 research group. Prediction of 90-day mortality after radical cystectomy for bladder cancer in a prospective European multicenter cohort. Eur Urol. 2014;66(1):156-63.

[6] Wessels F, Lenhart M, Kowalewski K, Braun V, Terboven T, Roghmann F, Michel M, Honeck P, Kriegmair M. Early recovery after surgery for radical cystectomy: comprehensive assessment and meta-analysis of existing protocols. World Journal of Urology. 2020;38(12):3139-53.

[7] Daneshmand S, Ahmadi H, Schuckman AK, Mitra AP, Cai J, Miranda G, Djaladat H. Enhanced recovery protocol after radical cystectomy for bladder cancer. The Journal of Urology. 2014;192(1):50-6.

[8] Tobert CM, Hamilton-Reeves JM, Norian LA, Hung C, Brooks NA, Holzbeierlein JM, Downs TM, Robertson DP, Grossman R, Nepple KG. Emerging impact of malnutrition on surgical patients: literature review and potential implications for cystectomy in bladder cancer. The Journal of Urology. 2017;198(3):511-9.

[9] White VJ, Guenter P, Jensen G, Malone A, Schofield M. Consensus Statement: Academy of Nutrition and Dietetics 
and American Society for Parenteral and Enteral Nutrition. J Parenter Enter Nutr. 2012;36(3).

[10] Hamilton-Reeves JM, Bechtel MD, Hand LK, Schleper A, Yankee TM, Chalise P, Lee EK, Mirza M, Wyre H, Griffin J. Effects of immunonutrition for cystectomy on immune response and infection rates: a pilot randomized controlled clinical trial. European Urology. 2016;69(3):389-92.

[11] Karl A, Rittler P, Buchner A, Fradet V, Speer R, Walther S, Stief GC. Prospective assessment of malnutrition in urologic patients. Urology. 2009;73(5):1072-6.

[12] Karl A, Staehler M, Bauer R, Tritschler S, Hocaoglu Y, Buchner A, Hoffmann J, Kuppinger D, Stief C, Rittler P. Malnutrition and clinical outcome in urological patients. European Journal of Medical Research. 2011;16(10): 469-72.

[13] Cerantola Y, Valerio M, Hubner M, Iglesias K, Vaucher L, Jichlinski $\mathrm{P}$, Are patients at nutritional risk more prone to complications after major urological surgery? The Journal of Urology. 2013;190(6):2126-32.

[14] Gregg JR, Cookson MS, Phillips S, Salem S, Chang SS, Clark PE, Davis R, Stimson C, Aghazadeh M, Smith JA. Effect of preoperative nutritional deficiency on mortality after radical cystectomy for bladder cancer. The Journal of Urology. 2011;185(1):90-6.

[15] Mathur S, Plank LD, Hill AG, Rice MA, Hill GL. Changes in body composition, muscle function and energy expenditure after radical cystectomy. BJU International. 2008; 101(8):973-7.

[16] Lambert JW, Ingham M, Gibbs BB, Given RW, Lance RS, Riggs SB. Using preoperative albumin levels as a surrogate marker for outcomes after radical cystectomy for bladder cancer. Urology. 2013;81(3):587-92.

[17] Taguchi S, Akamatsu N, Nakagawa T, Gonoi W, Kanatani A, Miyazaki H, Fujimura T, Fukuhara H, Kume H, Homma Y. Sarcopenia evaluated using the skeletal muscle index is a significant prognostic factor for metastatic urothelial carcinoma. Clinical Genitourinary Cancer. 2016;14(3):237-43.

[18] Kim TN, Choi KM. Sarcopenia: definition, epidemiology, and pathophysiology. Journal of Bone Metabolism. 2013;20(1):1.

[19] Pathak RA, Hemal AK. Frailty and sarcopenia impact surgical and oncologic outcomes after radical cystectomy in patients with bladder cancer. Translational Andrology and Urology. 2018;7(Suppl 6):S763.

[20] Tricco AC, Lillie E, Zarin W, O'Brien KK, Colquhoun H, Levac D, Moher D, Peters MD, Horsley T, Weeks L. PRISMA extension for scoping reviews (PRISMA-ScR): checklist and explanation. Annals of Internal Medicine. 2018;169(7):467-73.

[21] Bonau RA, Ang S, Jeevanandam M, Daly JM. Highbranched chain amino acid solutions: relationship of composition to efficacy. Journal of Parenteral and Enteral Nutrition. 1984;8(6):622-7.

[22] Ritch CR, Cookson MS, Clark PE, Chang SS, Fakhoury K, Ralls V, Thu MH, Penson DF, Smith JA. Jr, Silver HJ. Perioperative oral nutrition supplementation reduces prevalence of sarcopenia following radical cystectomy: results of a prospective randomized controlled trial. The Journal of Urology. 2019;201(3):470-7.

[23] Hensle T, Askanazi J, Rosenbaum L, Bernstein G, Kinney J. Metabolic changes associated with radical cystectomy. The Journal of Urology. 1985;134(5):1032-6.

[24] Hamilton-Reeves J, Holzbeierlein JM, Unger JM, Lew DL, Fisch MJ, Henry NL. A randomized phase III doubleblind clinical trial (S1600) evaluating the effect of immune-enhancing nutrition on radical cystectomy outcomes. American Society of Clinical Oncology, 2018.

[25] Kukreja JB*, Seif M, Lozano M, Wang X, Hwang H, Kamat A, Dinney C, Navai N. MP38-09 Preoperative immunonutrition in patients treated with radical cystecotmy, results from a phase 1,"Oral immunonutrition to enhance recovery after surgery" Feasibility trial. The Journal of Urology. 2019;201(Supplement 4):e537-e537.

[26] Lyon TD, Turner I, McBride D, Wang L, Gingrich JR, Hrebinko RL, Jacobs BL, Davies BJ, Tarin TV. Preoperative immunonutrition prior to radical cystectomy: a pilot study. The Canadian Journal of Urology. 2017;24(4):8895-901.

[27] Askanazi J, Hensle TW, Starker PM, Lockhart SH, LaSala P, Olsson C, Kinney JM. Effect of immediate postoperative nutritional support on length of hospitalization. Annals of Surgery. 1986;203(3):236.

[28] Roth B, Birkhäuser FD, Zehnder P, Thalmann GN, Huwyler M, Burkhard FC, Studer UE. Parenteral nutrition does not improve postoperative recovery from radical cystectomy: results of a prospective randomised trial. European Urology. 2013;63(3):475-82.

[29] Vidal A, Arnold N, Vartolomei MD, Kiss B, Burkhard F, Thalmann GN, Roth B. Oncological and functional outcomes of postoperative total parenteral nutrition after radical cystectomy in bladder cancer patients: A single-center randomized trial. International Journal of Urology. 2016; 23(12):992-9.

[30] McArdle AH, Reid EC, Laplante MP, Freeman CR. Prophylaxis Against Radiation Injury: The Use of Elemental Diet Prior to and During Radiotherapy for Invasive Bladder Cancer and in Early Postoperative Feeding Following Radical Cystectomy and Heal Conduit. Archives of Surgery. 1986;121(8):879-85.

[31] Deibert CM, Silva MV, RoyChoudhury A, McKiernan JM, Scherr DS, Seres D, Benson MC. A prospective randomized trial of the effects of early enteral feeding after radical cystectomy. Urology. 2016;96:69-73.

[32] Maffezzini M, Gerbi G, Campodonico F, Parodi D. A multimodal perioperative plan for radical cystectomy and urinary intestinal diversion: effects, limits and complications of early artificial nutrition. The Journal of Urology. 2006;176(3):945-9.

[33] Daly JM, Bonau R, Stofberg P, Bloch A, Jeevanandam M, Morse M. Immediate postoperative jejunostomy feeding: Clinical and metabolic results in a prospective trial. The American Journal of Surgery. 1987;153(2):198-206.

[34] Bertrand J, Siegler N, Murez T, Poinas G, Segui B, Ayuso D, Gres P, Wagner L, Thuret R, Costa P. Impact of preoperative immunonutrition on morbidity following cystectomy for bladder cancer: a case-control pilot study. World Journal of Urology. 2014;32(1):233-7.

[35] Hamilton-Reeves JM, Stanley A, Bechtel MD, Yankee TM, Chalise P, Hand LK, Lee EK, Smelser W, Mirza M, Wyre H. Perioperative immunonutrition modulates inflammatory response after radical cystectomy: results of a pilot randomized controlled clinical trial. The Journal of Urology. 2018;200(2):292-301.

[36] Declercq P, De Win G, Van der Aa F, Elodie B, Van der Linden L, Van Poppel H, Ludo W, Isabel S. Reduced length of stay in radical cystectomy patients with oral versus parenteral postoperative nutrition protocol. International Journal of Clinical Pharmacy. 2015;37(2):379-86.

[37] Lee CT, Chang SS, Kamat AM, Amiel G, Beard TL, Fergany A, Karnes RJ, Kurz A, Menon V, Sexton WJ. Alvimopan accelerates gastrointestinal recovery after radical 
cystectomy: a multicenter randomized placebo-controlled trial. European Urology. 2014;66(2):265-72.

[38] Bauer J, Capra S, Ferguson M. Use of the scored PatientGenerated Subjective Global Assessment (PG-SGA) as a nutrition assessment tool in patients with cancer. European Journal of Clinical Nutrition. 2002;56(8):779-85.

[39] Kondrup J, Rasmussen HH, Hamberg O, Stanga Z, A.a.h.E.W. Group, Nutritional risk screening (NRS 2002): a new method based on an analysis of controlled clinical trials. Clinical Nutrition. 2003;22(3):321-36.

[40] Swalarz M, Swalarz G, Juszczak K, Maciukiewicz P, Czurak K, Matuszewski M, Gajewska D, Słojewski M, Bogacki $\mathrm{R}$, Bryniarski P. Correlation between malnutrition, body mass index and complications in patients with urinary bladder cancer who underwent radical cystectomy. Advances in Clinical and Experimental Medicine. 2018;27(8):1141-7.

[41] Grimberg DC, Shah A, Molinger J, Whittle J, Gupta RT, Wischmeyer PE, McDonald SR, Inman BA. Assessments of frailty in bladder cancer, Urologic Oncology: Seminars and Original Investigations, Elsevier, 2020.

[42] Claps F*, Pavan N, Mir Maresma MC, Mazzon G, RamirezBackhaus M, Boltri M, Soria F, Massanova M, D'Andrea D, Traunero F. PD60-10 Impact of preoperative controlling nutritional status (conut) score on perioperative morbidity and survival outcomes in patients with bladder cancer treated with radical cystectomy: a multicenter analysis. The Journal of Urology. 2020;203(Supplement 4):e1278-e1278.

[43] Haifler M, Ventura Y, Malsha K, Shpitzer S, Zisman A, Baniel J, Amiel G, Hoffman A, Golan S. Neoadjuvant chemotherapy-induced sarcopenia to predict perioperative complications following radical cystectomy for bladder cancer. American Society of Clinical Oncology, 2020.

[44] Rawls W, Currin M, DeRosa A, Rosoff J, Roebel J, Jaenicke M, Beckham T, Hardie A, Prasad S. MP54-12 Sarcopenia as measured by iliopsoas and erector spinae muscle density is associated with higher incidence of postoperative complications following radical cystectomy for bladder cancer. The Journal of Urology. 2017;197(4S):e726-e726.

[45] Mayr R, Gierth M, Zeman F, Reiffen M, Seeger P, Wezel F, Pycha A, Comploj E, Bonatti M, Ritter M. Sarcopenia as a comorbidity-independent predictor of survival following radical cystectomy for bladder cancer. Journal of Cachexia, Sarcopenia and Muscle. 2018;9(3):505-13.

[46] Malmstrom TK, Miller DK, Simonsick EM, Ferrucci L, Morley JE. SARC-F: a symptom score to predict persons with sarcopenia at risk for poor functional outcomes. Journal of Cachexia, Sarcopenia and Muscle. 2016;7(1):28-36.

[47] Fávaro-Moreira NC, Krausch-Hofmann S, Matthys C, Vereecken C, Vanhauwaert E, Declercq A, Bekkering GE, Duyck J. Risk factors for malnutrition in older adults: a systematic review of the literature based on longitudinal data. Advances in Nutrition. 2016;7(3):507-22.

[48] Network BC. Eating Healthy During Bladder Cancer, 2017. https://bcan.org/eating-healthy-bladder-cancer/. (Accessed 04-20-2021.

[49] Vasdev N, Moon A, Thorpe AC. Metabolic complications of urinary intestinal diversion. Indian J Urol. 2013;29(4): 310-5.

[50] Jensen BT, Lauridsen SV, Jensen JB. Prehabilitation for major abdominal urologic oncology surgery. Current Opinion in Urology. 2018;28(3):243-50.

[51] Kaye DR, Schafer C, Thelen-Perry S, Parker C, Iglay-Reger H, Daignault-Newton S, Qin Y, Morgan TM, Weizer AZ, Kaffenberger SD. The Feasibility and Impact of a Presurgical Exercise Intervention Program (Prehabilitation) for Patients Undergoing Cystectomy for Bladder Cancer. Urology. 2020;145:106-12.

[52] Minnella EM, Awasthi R, Bousquet-Dion G, Ferreira V, Austin B, Audi C, Tanguay S, Aprikian A, Carli F, Kassouf W. Multimodal prehabilitation to enhance functional capacity following radical cystectomy: a randomized controlled trial. European Urology Focus (2019). 